\title{
Eça no teatro, o teatro em Eça
}

\section{Luiz Francisco Rebello}
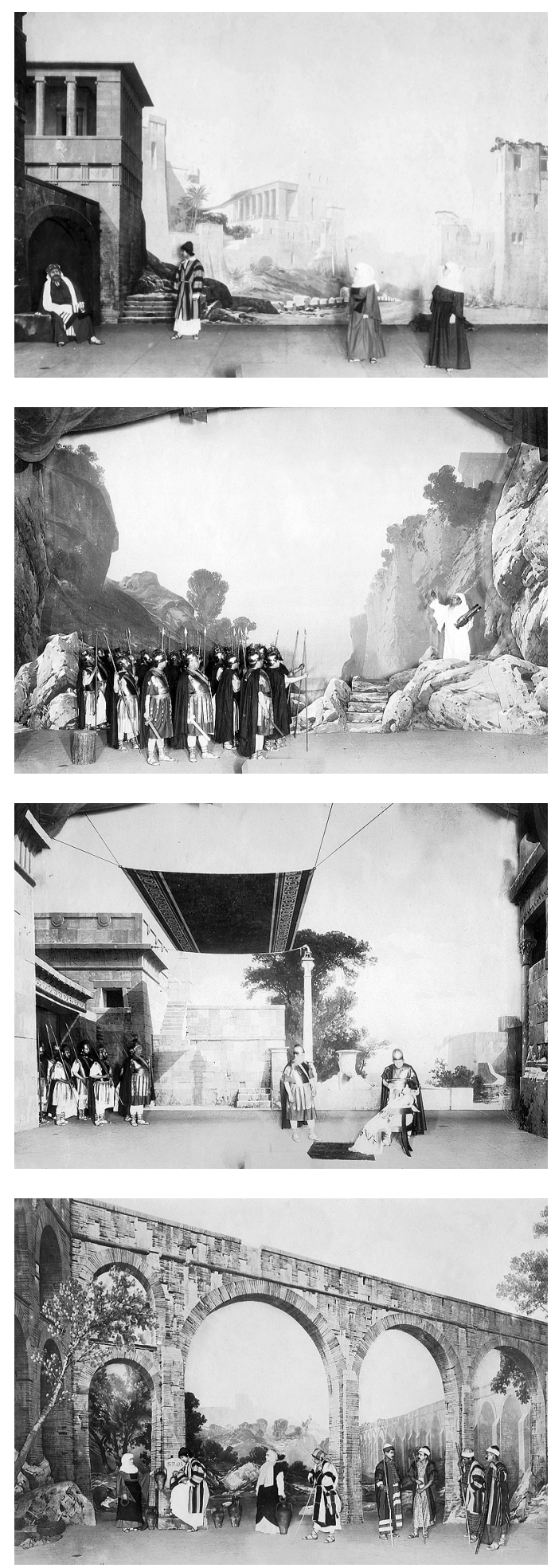

1.

Cumpriram-se, em 2008, exactamente cento e vinte anos sobre a publicação de Os Maias - "o único dos meus livros que sempre se me afigurou próprio a dar um drama patético, de fortes caracteres, de situações morais altamente comoventes", consoante opinava o seu autor numa carta dirigida ao escritor brasileiro Augusto Fábregas. Mas não seria ele a teatralizá-lo (embora houvesse chegado a elaborar um plano sequencial das cenas dos dois primeiros actos), nem seria esse o primeiro dos seus romances a ser transposto para o palco.

A carta em referência, datada de 6 de Maio de 1890, referia-se à adaptação de 0 crime do padre Amaro, empreendida pelo seu destinatário, e nesse ano representada, sem grande sucesso aliás, no Rio de Janeiro, onde havia sido editada em 1884. Eça confessava "nunca [ter pensado] nessa obra como sendo susceptivel de dramatização. 0 mesmo, fora Os Maias, pensaria das restantes - mas foi com uma dessas, 0 primo Basilio, que, em versão cénica de outro escritor brasileiro, Cardoso de Menezes, se havia iniciado, no próprio ano da publicação do romance (1878), a vasta série de peças através das quais se prolongou, no palco, a obra romanesca do ficcionista.

De Os Maias conhecem-se pelo menos três versões: de José Bruno Carreiro, escrita no princípio do século e estreada em 1945 no Teatro Nacional D. Maria II; de Norberto Barroca, levada à cena em 2004 no Teatro Experimental do Porto; e a mais recente, de António Torrado, já este ano estreada no Teatro da Trindade. Outras tantas existem de A reliquia (por Artur Ramos e Luis Sttau Monteiro, 1970; António Vitorino de Almeida e Helder Costa, 2000; Luis Assis, 2002); e há duas de 0 mandarim, a que foram dados títulos diferentes: Matar um homem na China (em romeno, sob a forma de um monólogo, em 1982), e Não matem o mandarim, de José Leitão (1995). 0 primo Basílio, além da versão brasileira já referida, foi representado, sem grande êxito também, no Teatro do Ginásio em 1916, transposto por Vaz Pereira (e adaptado ao cinema por Georges Pallu em 1923 e António Lopes Ribeiro em 1959). Do conto 0 suave milagre, extraiu 0 conde de Arnoso um "mistério em 4 actos e 6 quadros" para o qual Alberto de Oliveira escreveu os versos, Óscar da Silva compôs a música e Luigi Manini pintou os cenários, representada em 1901 no Teatro Nacional - e que foi severamente criticado por Fialho de Almeida. E, cingindonos a Portugal, mencionem-se, sem pretensão de ser-se exaustivo, as adaptações de $A$ capital, por Artur Ramos e Artur Portela (1971), 0 crime do padre Amaro, por Artur Portela e Mafalda Mendes de Almeida (1978), A tragédia da Rua das Flores, por Carlos Manuel Rodrigues (1981),
S.milagre

[Suave milagre,

de Eça de Queiroz] adapt. Conde d'Arnoso, Lisboa, Teatro Nacional D. Maria II, 1901 [cortesia do Museu Nacional de Teatro]. 


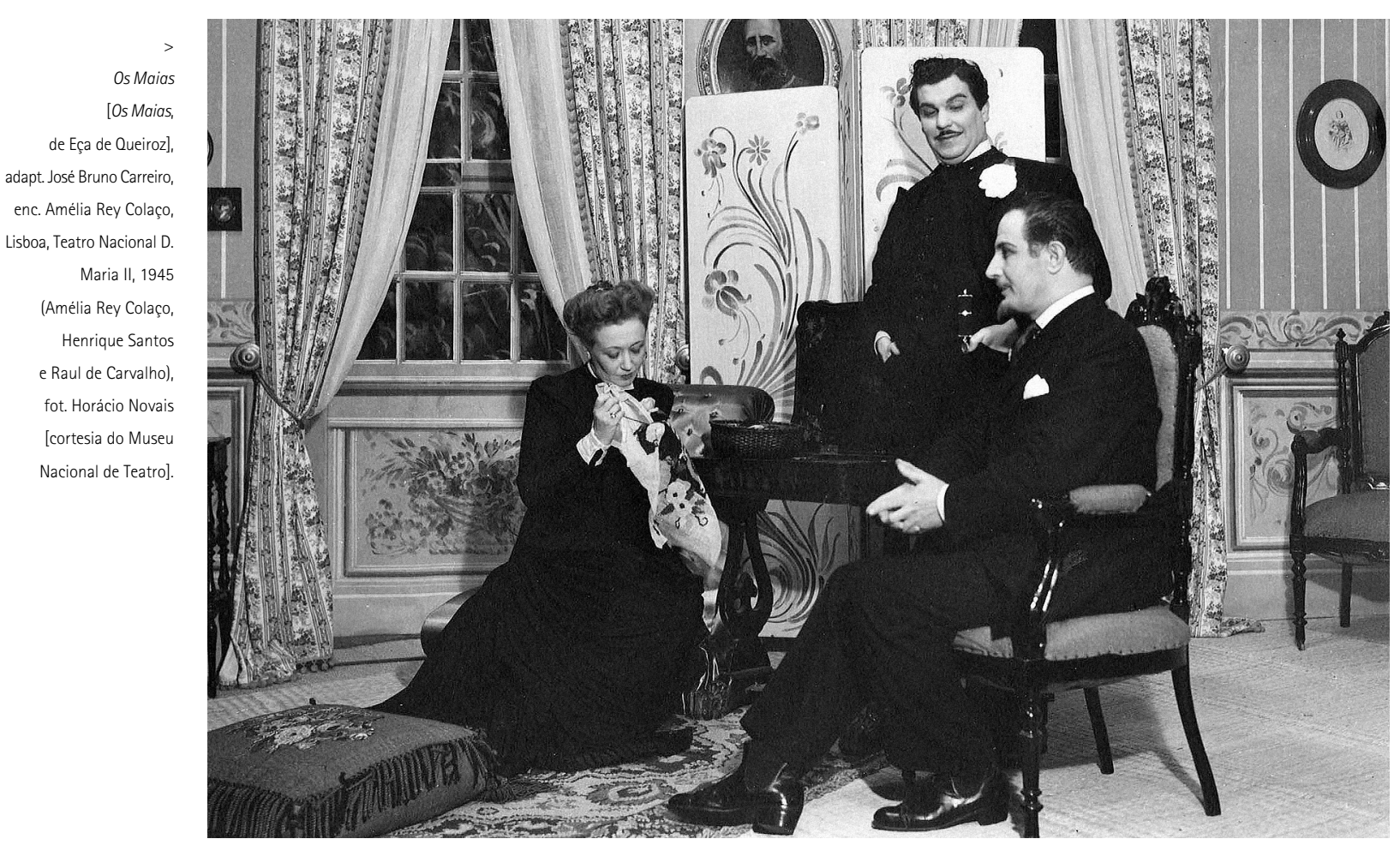

Alves \& C. ${ }^{a}$, por Fernando Gomes (1986) e Pedro Oliveira (1999), A ilustre casa de Ramires, por António Torrado (1995). De fora terão ficado apenas alguns dos contos, A cidade e as serras e 0 conde d'Abranhos, em que a diegese narrativa e a construção espácio-temporal se apresentam mais dificeis de compatibilizar com a morfologia específica da linguagem cénica.

Aquando da infausta representação brasileira de 0 primo Basilio, Machado de Assis, o grande romancista de Dom Casmurro, comentou o insucesso, a seu ver previsivel, entre outras razões porque "as qualidades do livro do $\mathrm{Sr}$. Eça de Queiroz e o talento deste, aliás forte, são as mais avessas ao teatro". Mas não tinha inteiramente razão. Se é certo que as diferenças semânticas e estruturais entre a linguagem novelesca e a linguagem cénica são notáveis, não é isso impeditivo de reconhecer-se, na ficção queirosiana, situações de um intenso dramatismo (ou de uma forte comicidade) e uma fluência dialogal de acentuada oralidade que a aproximam do teatro, ou pelo menos a ele são, sem grande esforço, reconduzíveis. A larga audiência dispensada a muitas - na realidade, a maioria - das adaptações acima recordadas, prova-o com exuberância.

A verdade é que o teatro - por ele considerado (e a este aspecto tornaremos adiante) uma questão de "importância pública", como para Garrett já era uma questão "de independência nacional" - nunca deixou de interessar (e preocupar) Eça de Queiroz. Estudante ainda interpretou no Teatro Académico de Coimbra, "com calções e cabeleira", o protagonista do drama de Teófilo Braga Poeta por desgraça - na ocorrência, o poeta arcádico Correia Garção - e traduziu o melodrama Philidor, de Joseph Bouchardy, o autor consagrado de Gaspar o serralheiro e 0 sineiro de $S$. Paulo, que muitas lágrimas fizeram derramar aos espectadores de Paris e de Lisboa.. e se inscreviam num tipo de teatro que viria a ser, mais tarde, alvo da sua irrisão.
Aliás o fascínio, quase diriamos a nostalgia, do teatro está latente, quando não patente, em boa parte dos seus escritos. A malograda tentativa de dramatização de Os Maias, a dramaticidade virtual da sua obra de ficção narrativa, a multiplicidade de referências ao teatro nos seus romances, crónicas e cartas, não deixam, a esse respeito, lugar a grandes dúvidas. E não é certo que 0 prólogo de 0 mandarim tem a forma de uma "comédia inédita", consistente num diálogo entre dois amigos que, "bebendo cognac e soda, debaixo d'árvores, num terraço à beira d'água", decidem "repousar do áspero estudo da realidade humana [e] partir para os campos do sonho"? Como não há-de considerar-se significativo que, para anunciar a futura evolução da sua obra, em que o real e o fantástico irão combinar-se, Eça se tenha servido do modo dramático?

2.

Ao nível da escrita dramatúrgica, porém, foi escasso o contributo da sua geração - a geração de 70. Ramalho Ortigão limitou-se a traduzir alguns textos paradigmáticos do romantismo francês (o Antony, de Dumas pai, em 1870; 0 marquês de Villemer, de George Sand, em 1874) e, do teatro espanhol, a Electra de Pérez Galdós; Oliveira Martins concebeu uma tetralogia histórico-filosófica de que apenas subsiste um Afonso VI, que se manteve inédito até há pouco tempo (1989). Teófilo Braga publicou vários dramas de matriz histórica, mediante os quais se propunha "darnos a lição objectiva dos grandes sucessos como uma animada experiência sociológica" (o citado Poeta por desgraça, 1865; Auto por desafronta e 0 lobo da Madragoa, 1865; Gomes Freire, 1907). Mas, se é reduzido o mérito de qualquer destas obras, particularmente importante foi o impulso que deu à investigação histórica sobre o nosso teatro, com os quatro tomos da sua pioneira História do teatro português (1870-1871), soma monumental que ainda hoje é fonte de consulta obrigatória, 

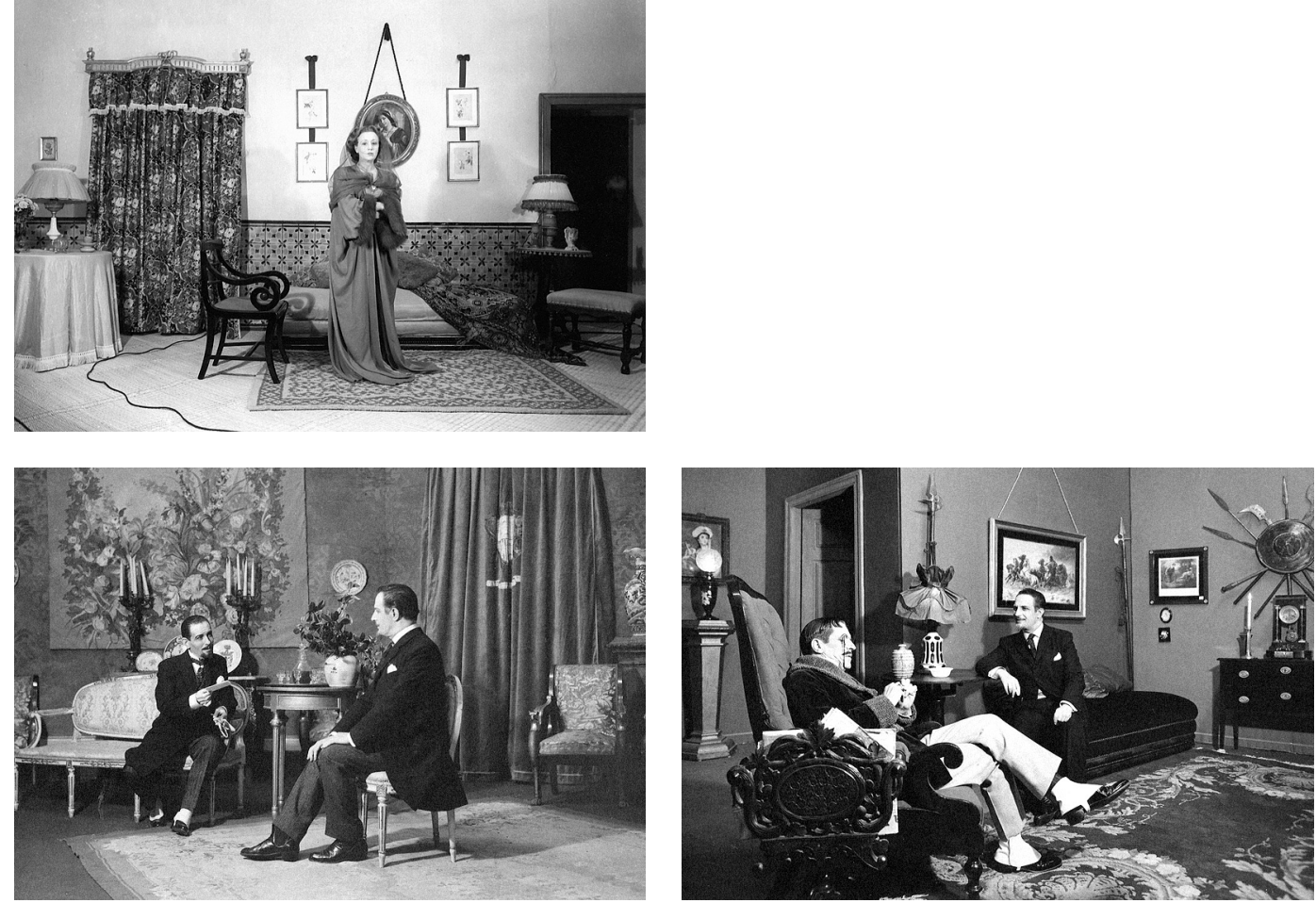

Os Maias

[Os Maias,

de Eça de Queiroz],

adapt. José Bruno Carreiro

enc. Amélia Rey Colaço,

Lisboa, Teatro Nacional D.

Maria II, 1945

( $\wedge$ Amélia Rey Colaço:

< José Gambôa

e Raul de Carvalho

> Samwell Diniz

e Raul de Carvalho),

fot. Horácio Novais

[cortesia do Museu

Nacional de Teatro]. não obstante os inevitáveis lapsos, omissões e preconceitos de indole positivista. De seu lado, Antero traduziu, com Jaime Batalha Reis, uma comédia musical de Sardou (0 degelo, 1875). E Guilherme de Azevedo traduziu, do mesmo autor, a Andréa (1876) e estreou no Teatro Nacional D. Maria II, em 1877, a comédia-drama Rosalino, que Rafael Bordalo Pinheiro, de quem foi colaborador no Álbum das glórias e no António Maria, definiu como "a expressão espirituosa da sensaboria lisboeta". A ele, e a Guerra Junqueiro, acobertados sob o pseudónimo "Gil Vaz comendador", se deveu a revista satírica Viagem à roda da Parvónia, representada uma única noite, em 1879, no Teatro do Ginásio, e "proibida à 1 da madrugada pelo Governador Civil", o caricato conselheiro Arrobas, de quem os estudantes de Medicina requereram se fizesse um exame à cabeça... Este "relatório da desmoralização política e social contemporânea", como um dos seus autores the chamou, pareceu a Antero, não obstante a virulência da crítica, anódino, porque "se há gangrena no corpo social - e tantos sintomas rapidamente acumulados a estão denunciando -, é o cautério, e o ferro em brasa, que convém aplicar-Ihe". Mas o estatuto acomodatício da revista dificilmente permitiria um tratamento tão drástico - que, mesmo atenuado, praticamente Ihe não pôde ser aplicado...

A que poderão atribuir-se este relativo alheamento da criação teatral e o saldo deficitário apresentado, ao invés do que aconteceu com as gerações anterior e posterior? Na 3. ${ }^{a}$ conferência democrática do Casino Lisbonense, Augusto Soromenho, professor do curso superior de Letras, havia considerado o drama, tal como nos palcos nacionais era dado a ver, "perverso, corrupto, falso e falto de probidade". E, um ano depois, Eça, ao analisar nas Farpas o estado do teatro, aludia à carência de "génio dramático" dos portugueses - para ele, "a nossa literatura de teatro toda se reduz ao Frei Luis de Sousa"; mas, trinta anos antes, não se havia surpreendido Garrett com "esta esterilidade dramática, esta como negação para o teatro em povo de tanto engenho como é o nosso"? Outros, como Carlos Reis, num dos seus magistrais estudos queirosianos, justamente a propósito da primeira transcrição cénica de Os Maias, preferiram imputar esse défice à inadequação ao modo dramático da estética naturalista, que Eça defendeu nas conferências do

Casino e Júlio Lourenço teorizou nos seus artigos da Revista de estudos livres (1884), depois reunidos em volume. Mas, a nosso ver, nenhuma destas explicações convence. A primeira, porque assenta num preconceito longamente enraizado, que restringe o teatro à sua exclusiva componente literária, e é desmentido por um património dramatúrgico de modo nenhum despiciendo. A segunda, porque "os cruciais desígnios ideológicos e sócio-culturais prosseguidos pelo Naturalismo" (cf. Reis 1984: 209) não inviabilizara, nem dela estão ausentes, o aparecimento da obra de autores como Ibsen e Strindberg, Hauptmann e Verga, Becque e Tchekov ou, à reduzida escala nacional, D. João da Câmara, Marcelino Mesquita, Manuel Laranjeira. Mais lógico seria procurar no descrédito, que a organização da actividade teatral no início do derradeiro terço do século XIX merecia aos homens de 70, a razão justificativa do seu distanciamento.

\section{3.}

A este respeito, é emblemático o citado artigo de As farpas sobre "O teatro em 1871", em que Eça retoma e desenvolve a temática de uma secção doutro, publicado no $1 .{ }^{\circ}$ fascículo, onde se passam em revista os diversos aspectos da sociedade portuguesa - a política, a religião, a imprensa, a literatura, a familia, os costumes e, bem entendido, 0 teatro.

0 diagnóstico é devastador: "0 teatro em Portugal vai acabando", "o teatro perdeu a sua ideia, o seu significado; perdeu até o seu fim". As causas dessa decadência radicam no "abaixamento geral do espírito e 


\section{Capa do programa do \\ espectáculo \\ A relíquia [A reliquia, de Eça de Queiroz], adapt. Luis de Sttau \\ Monteiro e Artur Ramos, enc. Artur Ramos, Lisboa, Teatro Maria Matos, 1970 \\ [cortesia do Museu Nacional de Teatro]}

Capa do programa do

espectáculo

Eça, percursos e 0 primo

Basilio, 2000

[cortesia do Museu Nacional do Teatro]

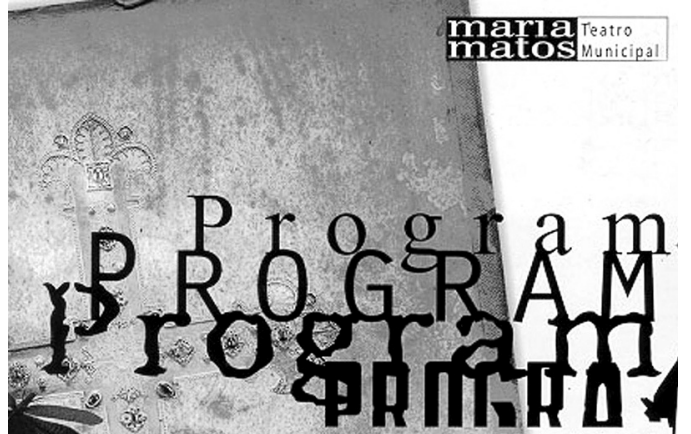

Maria Matos - Teatro Municipal

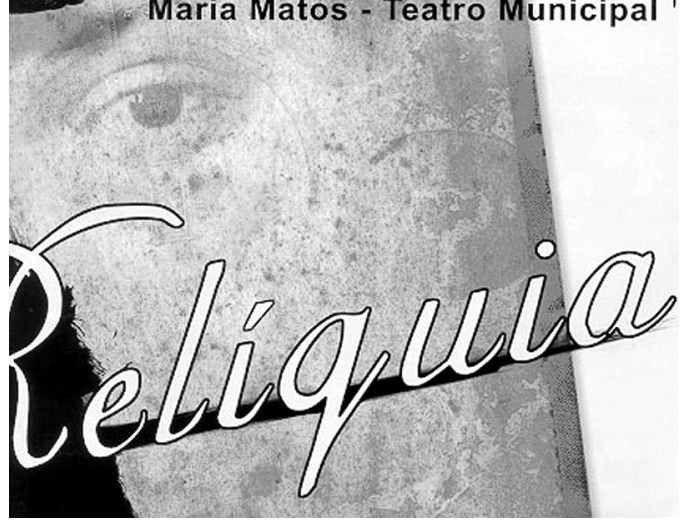

da inteligência [e] nas condições industriais e económicas dos teatros". E Eça desenvolve a sua análise pessimista, em alguns aspectos acaso excessiva, especificando: "0 público vai ao teatro passar a noite [...], não vai para assistir ao desenvolvimento duma ideia, nem sequer assistir à acção dum sentimento." A literatura dramática, em que abundam as traduções, feitas por "moços que ficaram no seu tempo reprovados no exame de francês", e as imitações que nos cartazes se dizem "originais" e são "uma cópia descarada" como já Augusto Soromenho havia denunciado, oscila entre farsas tão melancólicas como uma ruína e dramas tão cómicos como uma caricatura"... Acresce que "os actores em geral são maus, com excepção de quatro ou cinco individualidades inteligentes e estudiosas, que progridem [mais adiante citará José Anastácio Rosa e João Carlos dos Santos], - não tanto por incapacidade própria como pelas condições do seu destino: eles,

desgraçadamente, não pertencem a uma arte, pertencem a um ofício; não têm estudos, nem escola, nem incentivo, nem ordenados, nem público". E, por último, "a pobreza geral", e, porque "o teatro é caro, [...] a afluência aos teatros é pequena".

Desprotegido pelo Estado, que "não dá nada aos teatros" e os deixa entregues à "iniciativa particular, à concorrência" (mas, em contrapartida, subsidia largamente o S. Carlos, "uma inutilidade sentimental e luxuosa"), inscrito no quadro de uma sociedade amorfa e inerte, o teatro inevitavelmente definha, arrastando uma existência fruste. E no entanto, como Eça reconhece, "o teatro nacional é uma necessidade inteligente e moral". Daí que proponha a fundação de um teatro normal subsidiado, que se torne uma escola, um centro de arte, um elemento de cultura" - e faça "participar todo o pais do desenvolvimento da sua arte" pelas digressões da "companhia modelo" às principais cidades e pela formação de "pequenos e bons conjuntos teatrais na província". Vale a pena enfatizar como Eça defende aqui dois conceitos que iriam tomar corpo no século seguinte:

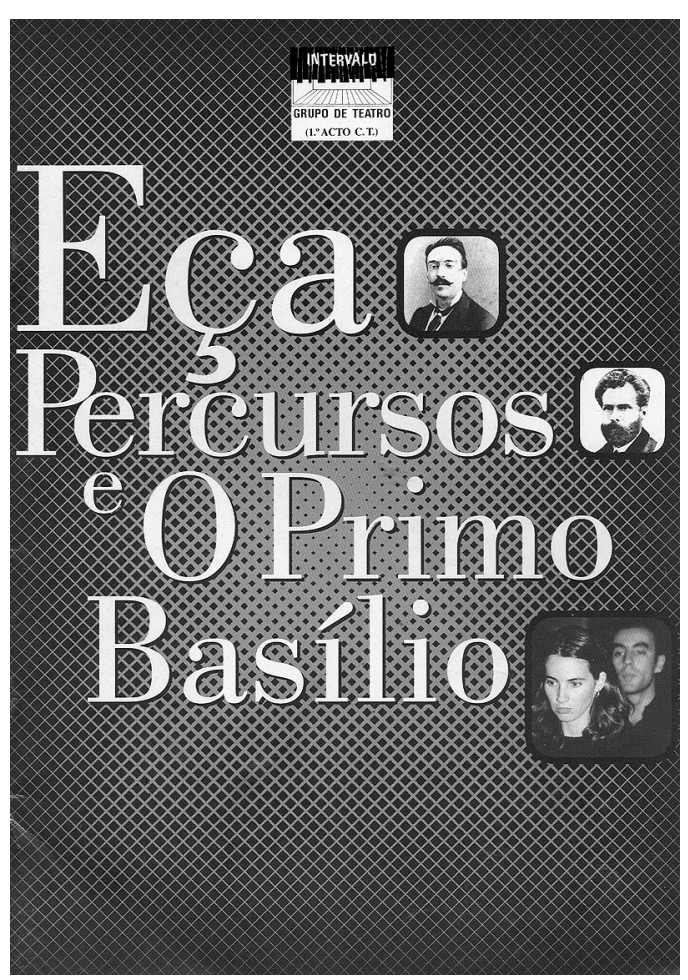

o teatro entendido como serviço público e a descentralização teatral.

\section{4.}

As pertinentes considerações de Luis Santos Ferro sobre a presença - e o papel - da música na obra de Eça de Queiroz aplicam-se, mutatis mutandis, ao teatro, não só na obra romanesca propriamente dita como nos restantes escritos. Diz ele: "0 levantamento sistemático das referências musicais na [sua] obra e a sua interpretação permitem afirmar que elas figuram não como mero elemento decorativo, acessório ou supérfluo na composição, mas antes na qualidade de componentes atentamente doseados e preenchendo função específica, ponderada, de efeito sabiamente calculado" (Ferro 1988: 422).

De quase todas as casas de espectáculos da capital o S. Carlos e o D. Maria, o Trindade, o Ginásio, o Variedades, o Rua dos Condes, o Príncipe Real, o Circo Price -, bem como do Porto (o Baquet, destruído pelo fogo em 1888, por desafortunada coincidência o ano de publicação de Os Maias), e até de Paris (a Comédie-Française, o Palais Royal, as Varietés, La Roulette de Montmartre...), se fala ao longo da obra queirosiana. Nalguns casos, apenas o nome é mencionado; noutros figuram como local de acção, em situações por vezes decisivas para o desenvolvimento diegético desta, ou ainda, conforme já vimos, como tema de reflexão sobre o modo e as condições de exercício da actividade teatral - de que são flagrante exemplo os dois citados artigos das Farpas.

S. Carlos é o teatro mais amplamente mencionado nessas páginas, com referência a esses dois niveis. 0 juizo sobre ele emitido é totalmente negativo: "nem criação de uma arte, nem formação de artistas, nem elemento de civilização, nem interesse geral do país" - e, absurdamente, é a ópera, não o teatro nacional, que o Estado subsidia. Sob este aspecto, era legítima a indignação de Eça.

Mas, num outro nível, o da trama romanesca, as 

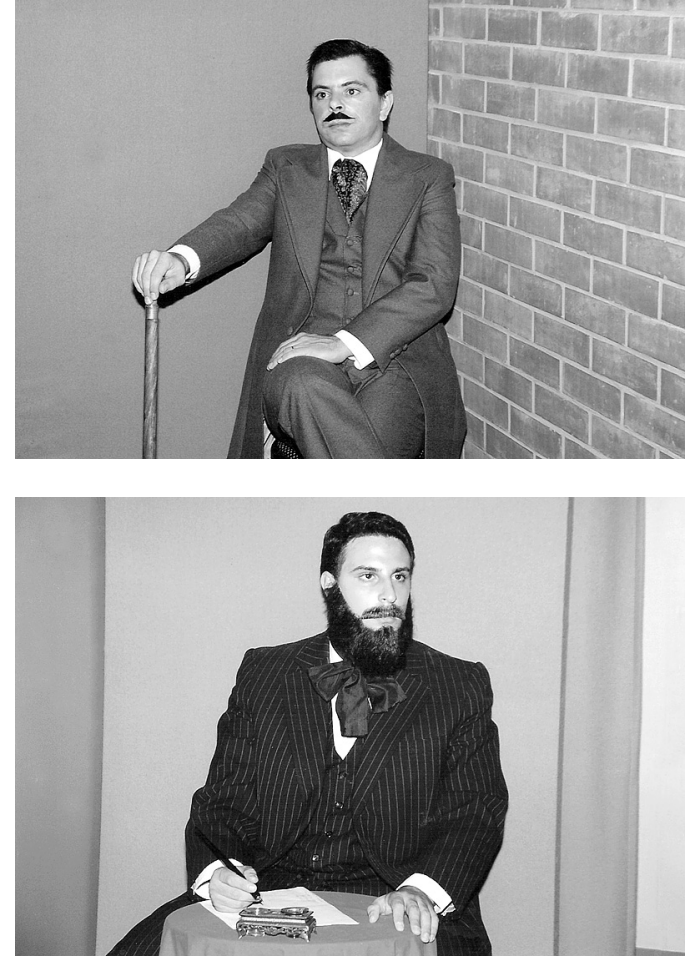

convergências são múltiplas: é em S. Carlos que Carlos da Maia assiste, na companhia do pianista e compositor Cruges, a uma desconsolada récita da Lucia di Lammermoor, de Donizetti, "em benefício, com a segunda dama" e o coro e os cantores a desafinarem; e que João da Ega o apresenta aos Gouvarinho num intervalo dos Huguenotes, de Meyerbeer. E é a S. Carlos que, numa noite em que se canta o Fausto, de Gounod, vão Luisa e Jorge, acompanhados por D. Felicidade, aos quais se reúne, mais tarde, o conselheiro Acácio, enquanto o amigo Sebastião, em casa deles, recupera as cartas trocadas entre Luisa e o primo Basilio, que a criada Juliana roubara. É ainda em S. Carlos que, na Relíquia, Teodorico e o Dr. Margaride assistem à representação do Poliúto, de Donizetti, e da Norma, de Bellini. Eé, finalmente, a S. Carlos que, recém-chegado da provincia, Artur Curvelo, em A capital, é levado pelo jornalista Melchior, mais para ver a assistência do que para ouvir $A$ africana e Roberto o Diabo, ambas de Meyerbeer, também com o coro e os tenores a desafinarem...

Outros teatros são também referidos, com maior ou menor relevância para a construção da fábula: o Trindade, onde decorre o famoso sarau literário de Os Maias (capítulo VIII), e onde, na Tragédia da Rua das Flores, Vitor e Genoveva - prefigurações de Carlos e Maria Eduarda - pela primeira vez se encontram durante uma representação do BarbaAzul, a famosa ópera-cómica de Offenbach, que ela havia visto em Paris, nas Varietés, e aqui se oferecia espectáculo pifio, com as coristas "enxovalhadas, os cabelos ignobilmente riçados, decotes lassos que descobriam clavículas necessitadas, cantando em tons agudos, pulando"... O D. Maria, frequentado por Sebastião (no Primo Basilio) e por Machado (em Alves \& C. . ); em relação a este último, somos informados de que a peça em cena era o melodrama (de Félix Pyat) 0 trapeiro de Paris, interpretado pelo actor Teodorico, uma das glórias do teatro romântico; o Ginásio, onde João da Ega assiste a uma récita de beneficência em que se representa a comédia 0 fruto proibido; o Circo Price,

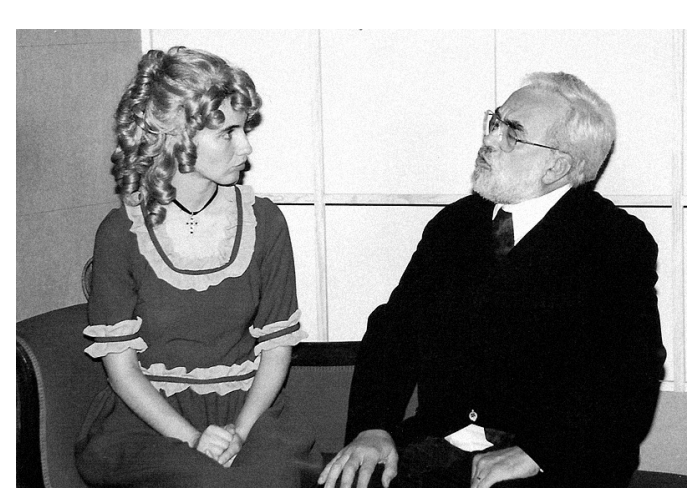

Eça, percursos e 0 primo Basilio,

adapt. Armando Caldas e Vaz Pereira,

enc. Armando Caldas, Intervalo Grupo de Teatro, 2000

( ^ Filipe Almeida;

$<$ Pedro Silva;

$>$ Silvia Alves

e Fernando Tavares Marques),

fot Armando Pinto. a que uma noite Genoveva e Vitor, na Tragédia, resolvem ir para sairem ainda antes do fim, enfastiados com o espectáculo soturno de uma plateia "quase vazia" e uma "péssima companhia"...

É sabido que os três últimos lustros da vida de Eça de Queiroz decorreram na capital francesa, para onde fora nomeado cônsul em 1888. A marca de teatro que ai (Ihe) era dado a ver não podia deixar de ficar impressa nos seus escritos. E, de facto, nos Ecos de Parise nas Cartas familiares, encontram-se diversas referências a alguns espectáculos em cena: a Antigona, de Sófocles, na Comédie-Française, Les rois, de Jules Lemaître, com a grande Sarah Bernhardt, na Renaissance (1893), o Thermidor, de Victorien Sardou, "sagaz cozinheiro de guisados teatrais", na Porte-St. Martin em 1896, cinco anos após a forçada interrupção das representações na Comédie. E, passando ao território da ficção, é em A cidade e as serras que maior número de citações se nos deparam: Jacinto e Zé Fernandes vão à Ópera ouvir o Lohengrin e às Varietés assistir à óperacómica (de Hervé) La femme à papa: o segundo vê, nesta última sala, "uma comédia muito fina, muito aclamada, toda faiscante do mais vivo parisianismo, em que todo o enredo se enrodilhava à volta duma cama"; e é a ele que o grão-duque Casimiro conta ter visto, num teatrinho de Montmartre, La Roulette, uma revista "engraçada e bem despida", Para cá as mulheres... Não se nomeiam os autores desta revista e daquela comédia (nem lográmos identificálos); mas, esparsas, há referências a outros dramaturgos, sobretudo Shakespeare, que é mencionado logo no primeiro parágrafo de 0 Egito e, repetidamente, nas Prosas bárbaras, uma das quais é inteiramente dedicada a uma análise de Macbeth, a propósito da ópera de Verdi, e ainda Ésquilo, o Molière de Don Juan, Lope de Vega, Racine, Beaumarchais, Pixérécourt, Victor Hugo, Labiche... e nenhum português para além de Garrett. Nem, tão-pouco, se nos depara qualquer referência aos primeiros frutos do grande movimento renovador da cena que então eclodia: o Teatro 


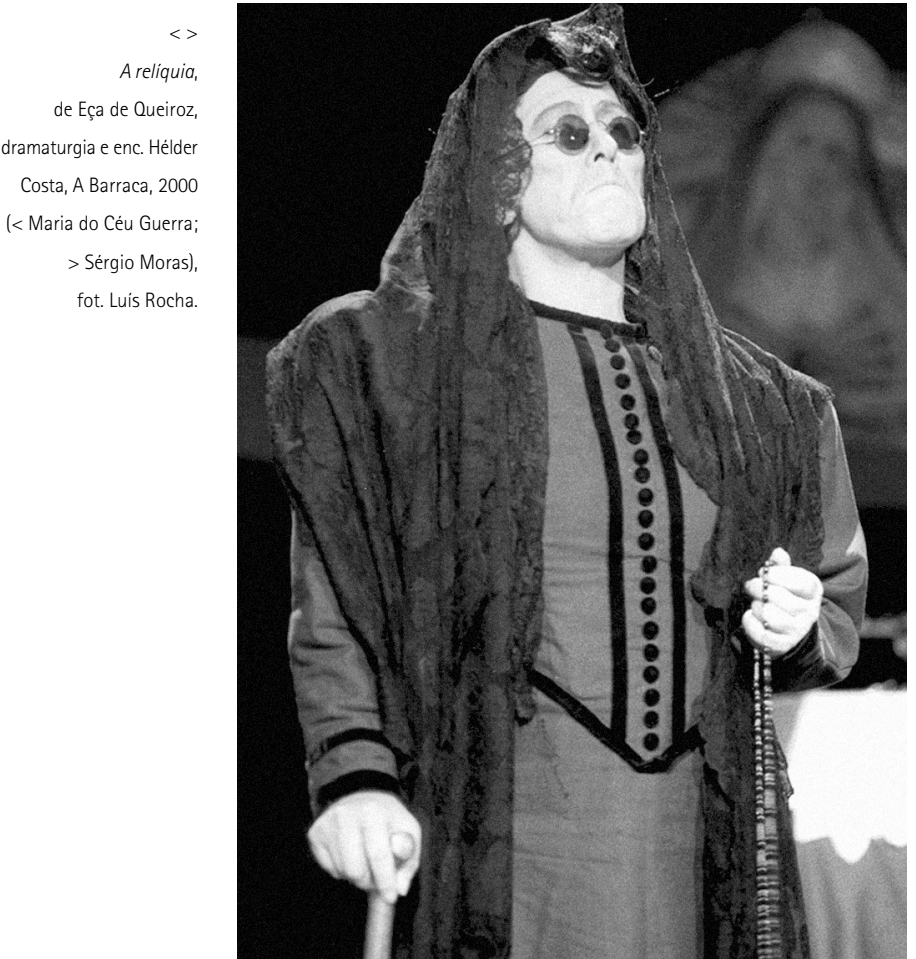

Livre de Antoine (1887), o Teatro de Arte (1891), a obra de Ibsen, Strindberg, Maeterlinck.

5.

Num outro plano, várias são as personagens da ficção queirosiana que mantêm ligações ao teatro, quer nela ocupem lugar relevante, quer se trate de simples comparsas, e quer essa ligação respeite à escrita teatral ou à representação cénica.

Entre os autores, ou candidatos a autores, a galeria e vasta, e geralmente irrisória. Ai estão o Alencar de Os Maias, "o ilustre cantor da Voz d'aurora, o estilista de Elvira, o dramaturgo do Segredo do comendador", e, no mesmo romance, o músico Cruges, autor de uma ópera-cómica, Flor de Granada, e o ministro da Marinha Sá Nunes, futuro presidente do Ministério, autor de El-Rei Bolacha, "a grande mágica da Rua dos Condes", cujo título remete para o rei Bobeche do Barba-Azul. Ai está Artur Curvelo, o protagonista de $A$ capital, que, depois de hesitar em escrever "uma comédia à Sardou [e] um drama à Victor Hugo", opta por um drama em 5 actos, Amores de poeta, por ele definido como "a luta entre o talento e os preconceitos sociais", de que lê, entre bocejos e risos sufocados, algumas cenas aos convidados para um jantar no Hotel Universal. Ai está Ernestinho Ledesma, "pequenino, linfático", que vivia com "uma actrizita do Ginásio", autor de traduções, dois originais num acto, uma comédia de calembourgs e, também ele, um drama em 5 actos, Honra e paixão, destinado ao Teatro das Variedades, onde se estreou com grande êxito e valeu ao autor "uma formosa coroa de louros", cujo entrecho antecipa o adultério de Luísa com o primo Basílio. Por fim no Conde d'Abranhos, fala-se de "um jovem poeta, filho de um influente, [que] viera [a Lisboa] implorar a protecção do conde", então deputado, autor do drama Vingança dum rival, mas que "sofreu no fim o desgosto duma pateada memorável"... 0 resumo do entrecho de alguns desses dramas, os seus títulos, os fragmentos que deles são dados

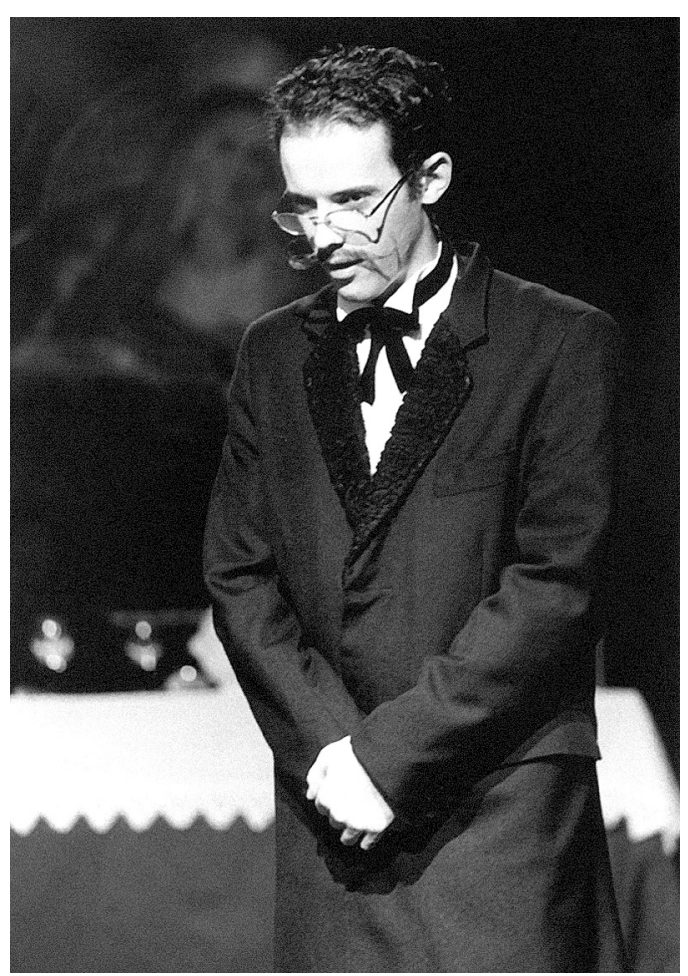

a conhecer, servem ao romancista para caricaturar certeiramente - e impiedosamente - o segmento dominante da literatura dramática do seu tempo, que tão duramente reprovara nos artigos das Farpas.

Restam os actores e os cantores, que passam fugidiamente por alguns dos romances - o Cardoso, "galã da Trindade" (0 crime), um outro galã, mas este do Ginásio, Alfredo ( 0 conde), o actor Cordeiro, "moço galante e tímido, [que] torcia constantemente, num gesto maquinal, um pequeno buço castanho" (A capita), o cantor Sarrotini, "um grande pândego, um maganão delicioso", que se exprime numa algaravia de italiano e espanhol e é descrito como segundo baixo de S. Carlos na Capital e baritono na Tragédia; e, apenas mencionados de passagem, entre personagens imaginadas e artistas que realmente actuaram em S. Carlos, a bailarina Vizenti, o tenor Corcelli, Pandolli, Nicolini, a Patti, a Sassi, o tenor Bertoni, cujo regresso a Itália deixou livre o andar da rua de S. Francisco que Maria Eduarda iria alugar ao Cruges e onde Carlos da Maia a conheceu. Digamos que a sua função, nos livros em que comparecem, é tão-só a de compôr o quadro social e humano em que a acção romanesca se inscreve - e de que o teatro, factor estruturante da vida em sociedade, não poderia, obviamente, estar ausente.

\section{Referências bibliográficas}

FERRO, Luis Santos (1988), "Música", in A. Campos Matos (coord.), Dicionário de Eça de Queiroz, Lisboa, Editorial Caminho.

PINTO, Júlio Lourenço(1885), Estética naturalista, Porto, Livraria Portuense. QUEIROZ, José Maria Eça de (1970), Obras completas, 2 vols., Rio de Janeiro, Editora Aguilar.

REIS, Carlos (1970), "Eça d Queiroz: À procura do tempo perdido", Os Maias, Adaptação Teatral deJosé Bruno Carreiro, Lisboa, IN - CM.

SALGADO JÚNIOR, António (1930), História das Conferências do Casino, Lisboa, s/e [Tipografia Cooperativa Militar] 


\section{Alguns espectáculos baseados na vida e obra de Eça de Queiroz}

Lista organizada por Sebastiana Fadda

Fontes: Luiz Francisco Rebello e CETbase [http://www.fl.ul.pt/CETbase/default.htm].

1878 - O primo Bazílio, versão de Cardoso de Menezes [Brasil].

1890 - O crime do padre Amaro adapt. Augusto Fábregas [Rio de Janeiro].

1901 - Suave milagre Sociedade Artistica [companhia residente do Teatro Nacional D. Maria II], adapt. Conde d'Arnoso.

1916 - Primo Bazílio, Teatro do Ginásio, adapt. Vaz Pereira, enc. Maria Matos.

1945 - Os Maias Companhia Rey Colaço-Robles Monteiro, adapt. José Bruno Carreiro, enc. Amélia Rey Colaço.

1970 - A relíquia, prod. Igrejas Caeiro, adapt. Luis de Sttau Monteiro e Artur Ramos, enc. Artur Ramos.

1971 - A capital G.A.T. - Grupo de Acção Teatral, adapt. Artur Ramos e Artur Portela-Filho, enc. Artur Ramos.

1978 - $O$ crime do padre Amaro Teatro Maria Matos, adapt. Artur Portela-Filho e Mafalda Mendes de Almeida, enc. Armando Cortez.

1981 - A tragédia da Rua das Flores Repertório - Cooperativa Portuguesa de Teatro, adapt. Carlos Maria Rodrigues, enc. Armando Cortez.

1982 - Matar um homem na China Teatro Nacional de Bucareste [Roménia], enc. Dorel Neagu Jacobescu.

1985 - São Cristóvão, O Bando, texto de Cândido Ferreira (fontes não identificadas), enc. João Brites.

1985 - Ofício número barra oitenta e cinco, ContraRegra, Centro de Actividades Culturais e de Produção de Espectáculos, textos de vários autores, enc. Antonino Solmer.

1986 - Alves \&t $C$. ${ }^{a}$

TAS - Teatro Animação de Setúbal, enc. Fernando Gomes.

1986 - $O$ tesouro

Zona 2 (Escola Primária n. 9 Chelas), versão de J. A. Gouveia, enc. Geraldo Tuché e J. A. Gouveia.
1986 - O tesouro,

Cena - Companhia de Teatro de Braga, adapt. Manuel G. Correia, enc. António Moreno.

1995 - Os Maias

TIO - Teatro Independente de Oeiras, enc. Carlos d'Almeida Ribeiro.

1995 - Não matem o mandarim!, Teatro Art'Imagem, dramaturgia e enc. José Leitão.

1995 - A ilustre casa,

Teatro do Noroeste - Centro Dramático de Viana do Castelo, adapt. António Torrado, dramaturgia e enc. Jorge Castro Guedes.

1999 - Alves \&t C. ${ }^{a}$,

0 Nariz - Teatro de Grupo, adapt. e enc. Pedro Oliveira.

2000 - Madame,

Teatro Nacional D. Maria II [companhia], TNSJ Teatro Nacional S. João, texto de Maria Velho da Costa, enc. Ricardo Pais.

2000 - Que relíquia!, Teatro Art'Imagem, adapt. e enc. José Leitão.

2000 - A relíquia, A Barraca, versão de António Vitorino de Almeida, dramaturgia e enc. Hélder Costa.

2000 - Eça, percursos e $O$ primo Basílio, Intervalo - Grupo de Teatro, adapt. de O primo Basílio por Vaz Pereira, dramaturgia e enc. Armando Caldas.

2001 - Os Maias

CDIAG - Centro Dramático Intermunicipal Almeida Garrett - Teatro da Malaposta, adapt. José Bruno Carreiro, enc. Orlando Costa.

2001 - Episódio da vida romântica, dramaturgia e enc. Norberto Barroca.

2001 - Alegre campanha,

Grupo de Teatro Maizum, dramaturgia e enc. Silvina Pereira.

2002 - A relíquia,

Cassefaz, versão e enc. Luís Assis.

2002 - Os Maias

Baal 17, Companhia de Teatro na Educação do Baixo Alentejo, enc. Luis Raposo Cruz. 

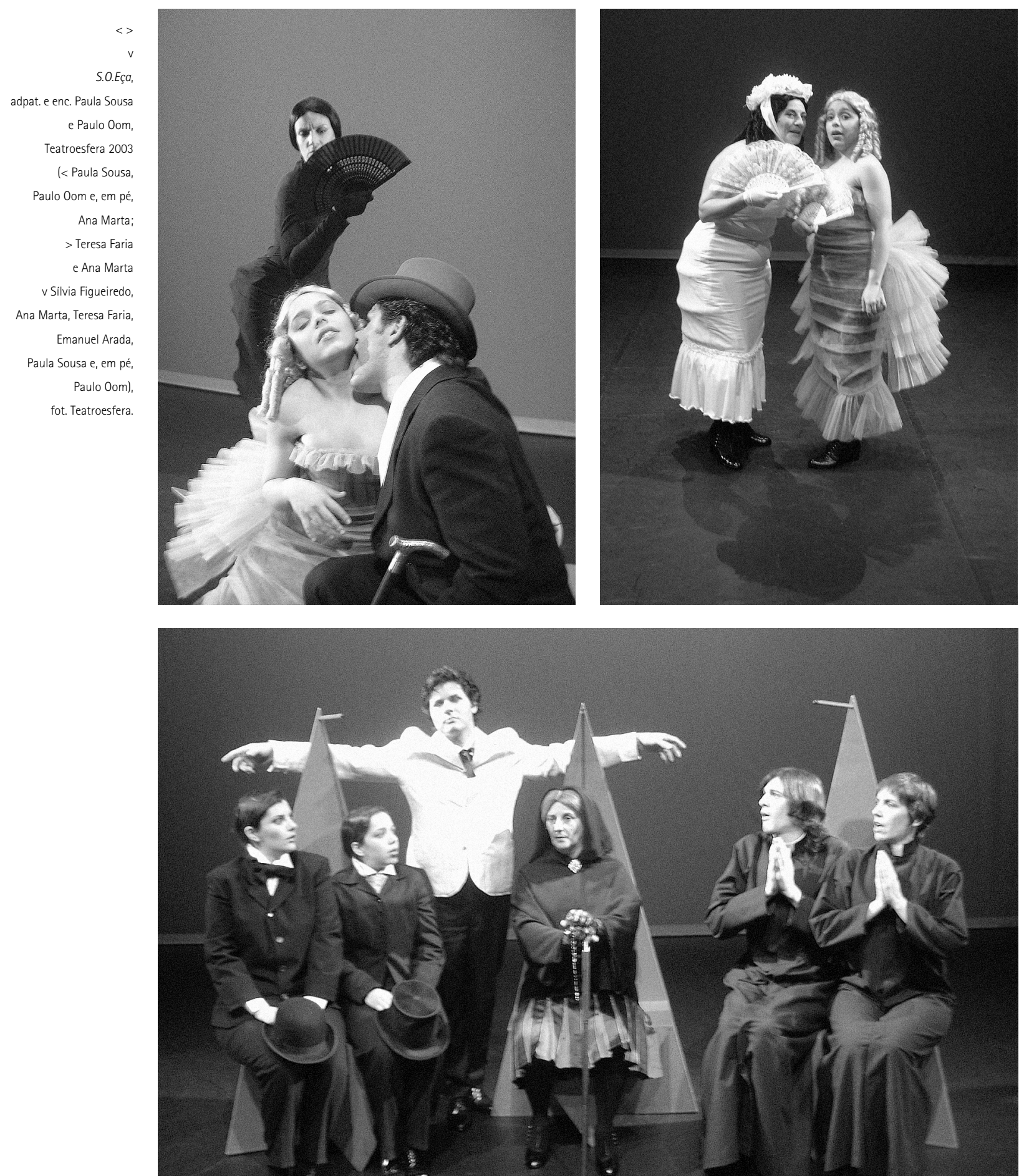

\section{2 - The Maias}

Galleon Theatre Company [Inglaterra], adapt. Alice de Sousa, enc. Bruce Jamieson.

2003 - S.O.Eça,

Teatroesfera, dramaturgia e enc. Paula Sousa e Paulo Oom.

2004 - Os Maias: Crónica social romântica,

TEP - Teatro Experimental do Porto, adapt. e enc. Norberto Barroca.

2005 - D’Eça,

Pequeno Palco de Lisboa, adapt. José Mateus e Rui Luís Brás, enc. Rui Luis Brás.

2006 - Os Maias
Escolas Secundárias de Odivelas, enc. Jorge Estreia.

2007 - $O$ defunto

[ópera de câmara], Grupo de Música

Contemporânea de Lisboa, adapt. para ópera do compositor Daniel Schevtz, libreto e enc. Érica Mandillo, dir. mus. João Paulo Santos.

2008 - $O$ crime do padre Amaro, Galharufas Produções, Teatro do Parque, adapt. Taveira Júnior e Lúcio Lombardi, dir. Lúcio Lombardi [Recife].

2009 - Os Maias no Trindade, Teatro da Trindade, adapt. António Torrado, enc. Rui Mendes. 


\section{$\mathrm{APCT}$ 开, \\ Associação Portuguesa de Críticos de Teatro

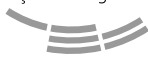

Presidente honorário

Direç̧ão

Assembleia Geral

Conselho Fiscal

ESTATUTOS
Luiz Francisco Rebello

Maria Helena Serôdio

João Carneiro

Rui Pina Coelho

Paulo Eduardo Carvalho

Sebastiana Fadda

Ana Isabel Vasconcelos

Mónica Guerreiro

Rita Martins

Capítulo Primeiro (Da Associação e dos seus fins)

Art. ${ }^{2} .^{\circ}$

A Associação tem por objectivo:

Dignificar, estruturar e responsabilizar a actividade crítica relativa à teoria e prática do teatro, entendendo-se por actividade crítica não só a crítica de espectáculos, mas também tudo aquilo que diga respeito à informação, reflexão e teorização no campo das artes performativas.

\section{Colaboração com Sinais de cena}

A revista está aberta à participação de quem deseje colaborar enviando artigos que julgue corresponderem aos objectivos da publicação e às modalidades enunciadas pelas rubricas existentes. A consulta do sítio da APCT na Internet (www.apcteatro.org) e o contacto por correio electrónico (estudos.teatro@fl.ul.pt) são indispensáveis para conhecer as normas de apresentação dos artigos (dimensão, aspecto gráfico, citações, referências bibliográficas, ilustrações, etc.).

\section{ASSINATURA}

Desejo subscrever os números 12 e 13 da revista Sinais de cena (correspondentes a Dezembro de 2009e Junho de 2010), no valor total de $22,00 €$ beneficiando assim de um desconto sobre o preço de venda ao público.

Fora do pais: Europa $24,00 €$ / Fora da Europa $26,00 €$.

Nome:

Morada:

\begin{tabular}{l|l} 
Código postal: & Pais:
\end{tabular}

Endereço electrónico:

\begin{tabular}{ll|l} 
Forma de pagamento: $\quad \square$ Vale postal $\quad \square$ Cheque n. & Banco
\end{tabular}

(passar à ordem de Associação Portuguesa de Criticos de Teatro)

Preencha e envie este cupão (ou fotocópia do mesmo) para:

Data:

\section{Sinais de cena}

Centro de Estudos de Teatro

Faculdade de Letras de Lisboa: sala 67

Alameda da Universidade

1600-214 Lisboa (Portugal) 
